\title{
La(s) Modernidad(es) y su Razón excluyente
}

\section{Modernity(ies) and its Excluding Reason}

\author{
Jairo Marcos ${ }^{1}$ \\ UNED-UNAM (España-México)
}

Recibido: 02-07-18

Aprobado: 29-06-19

\section{Resumen}

Una revisión filosófico-histórica a las diversas caras de la Modernidad refleja la primera experiencia del Yo europeo con el extranjero bajo esquemas de dominación y violencia. La ontología europea no surge de la nada: el 'yo conquisto' antecede histórica y fundacionalmente al 'yo pienso' cartesiano. Ir más allá la Razón excluyente, alimentada con los mitos que todavía mantienen a Europa, exige el abandono del discurso eurocéntrico y de su racionalidad, cuyo logos univocista se mantiene en pie a pesar de las múltiples sospechas que levanta. Desde los mimbres transformadores de Lèvinas y Vattimo, dos de los filósofos con más conciencia de las otredades, este ensayo no trata de negar la Razón, sino que invita a ir más allá de ésta, allí donde no necesariamente se encuentran la sin-razón ni la irracionalidad. Para que la esperanza de las víctimas no quede definitivamente frustrada.

Palabras-clave: Modernidad, Razón, racionalidad, Europa, Otro.

\begin{abstract}
A philosophical-historical review of the various faces of Modernity reflects the first experience of the European ego with foreigners under patterns of domination and violence. European ontology does not come from nothing: the 'I conquer' precedes historically and foundationally the Cartesian 'I think'. Going beyond the exclusive reason, nourished by myths that still

\footnotetext{
${ }^{1}$ (jmarcos@desplazados.org.) Doctorando en Filosofía y periodista freelance para medios españoles y extranjeros. Autor de tres libros y varios artículos premiados, sus publicaciones y perfil profesional pueden leerse en www.desplazados.org. Este ensayo forma parte de la tesis en la que está sumergido: 'nos-Otras, las víctimas. Pensar desde las periferias: transformaciones de la Filosofía', codirigida por Juan José Sánchez (UNED, España) y Horacio Cerutti Guldberg (UNAM, México).
} 
maintain Europe, demands the abandonment of the Eurocentric discourse and its rationality, whose univocal logos remains standing despite the multiple suspicions it raises. From the transforming wickers of Lèvinas and Vattimo, two of the philosophers with more awareness of otherness, this essay does not try to deny Reason, but invites to go beyond it, where not necessarily wait nonreason neither irrationality. So that the hope of the victims is not definitively frustrated.

Key-words: Modernity, Reason, rationality, Europe, Other.

\section{Introducción}

La Modernidad temprana o primera Modernidad (1492-1875) trae consigo el arranque del imperio moderno y su colonialismo. Abya Ayala originariamente y las ÁfricaS después serán las primeras exterioridades vejadas por la autoafirmación de lo Mismo. España y Portugal protagonizan esta etapa inicial, aunque el Gran Relato los deja de lado, y con ellos, al siglo XVI hispanoamericano ${ }^{2}$, incluido como el fin de la Edad Media. Reconocidos geográficamente los territorios, se pasa al control de los cuerpos; lo hacía un Hombre ${ }^{3}$ concreto: el guerrero europeo, primer hombre moderno activo. Esa primera experiencia del Yo europeo con el extranjero se produjo bajo esquemas de superioridad cuasi-divina sobre las periferias, los bárbaros. La expresión 'encuentro entre dos mundos' es un eufemismo, pues lo que se produjo fue la destrucción violenta de una de las partes, en un choque antropológico devastador para el ecosistema indígena ${ }^{4}$. "Cuando Cristóbal Colón llegó a América, vivían allí unos setenta millones de personas. Cien años después, el noventa por ciento de la población original había sido exterminada a causa de la enfermedad, el hambre y los abusos laborales" 5 .

\footnotetext{
${ }^{2}$ El giro decolonial desvela que el despertar de Europa se produce desde el Oeste hacia el Este y del Sur (conectado además con el mundo musulmán y africano) al Norte.

${ }^{3}$ La mayúscula también es reveladora porque confirma el carácter patriarcal de la dominación: "El conquistador es macho. (...) La madre de América no es España, es Amerindia. (...) España no es la 'madre patria', es el 'padre patria'”. En Dussel, Enrique: Caminos de liberación latinoamericana II: teología de la liberación y ética. Buenos Aires: Latinoamérica Libros, 1974, p. 118.

${ }_{4}$ Así lo considera el fraile dominico Bartolomé de las Casas, quien reconoce el derecho de los pueblos indígenas a rechazar la imposición europea, en lo que supuso el primer gran discurso crítico sobre la Modernidad dentro de la propia Modernidad. Ni siquiera llega a tal grado de reconocimiento del Otro amerindio Francisco de Vitoria, considerado el fundador del Derecho Internacional. En las antípodas del pensamiento lacasiano se sitúa la defensa de la guerra justa de Ginés de Sepúlveda. Ver Sandoval, Canek: "Teoría de la guerra justa de Ginés de Sepúlveda: prototipo imperialista y cristiano". Ed. Hernanz, José Antonio. Xalapa: Universidad Veracruzana, 2013 [TFG No publicado].

${ }^{5}$ Rendueles, César: Capitalismo canalla: una historia personal del capitalismo a través de la literatura. Barcelona: Seix Barral, 2015, p. 124.
} 
Los períodos posteriores son el fruto de un siglo y medio de Modernidad, efecto y no causa de estos precedentes pasos modernos. La hegemonía hispánica perdura hasta que las provincias holandesas constituyen su propio imperio naviero: ya no es posible el imperio territorial, deseo que es sustituido por un modelo puramente comercial y mercantil. Es en Ámsterdam donde se forma intelectualmente Descartes, dato nada baladí pues su ego cogito es consecuencia del ego conquiro. La ontología europea no surge de la nada: el 'yo conquisto' antecede histórica y fundacionalmente al 'yo pienso' cartesiano. Armazón teórico del 'yo conquisto' América, del 'yo esclavizo' a las ÁfricaS, del 'yo venzo' en las guerras de la India y China, el ego cogito no se despoja de estos pilares cuando se convierte en divino $\left(\mathrm{Hegel}^{6}\right)$, en La voluntad de poder (Nietzsche ${ }^{7}$ ), o en el más discreto ego cogito cogitatum (Husserl ${ }^{8}$ ). Es la colonización, el cuarto momento de esta primera etapa tras la invención, el descubrimiento, y la conquista. Colonización militar y violenta pero también política, económica, de género9 ${ }^{9}$, cultural, social y religiosa.

La debilidad geográfica y poblacional de Holanda acerca el ocaso de la Modernidad temprana. Gran Bretaña, junto con Francia y otras potencias nórdicas, alberga la Revolución Industrial y toma el relevo. Es la confirmación del colonialismo y el auge del esclavismo; es el siglo del empirismo inglés de Hobbes (propulsor de un modelo solipsista ${ }^{10}$ ) y de Locke (fundamento del nuevo poder ${ }^{11}$ ). Pero todavía por aquellos años China y el Indostán conservaban una posición de superioridad: "El conjunto del orden económico mundial era sinocéntrico" 12 , si bien los europeos lograron acceder a este comercio

\footnotetext{
${ }^{6}$ Ver Hegel, G. W. Friedrich: Fenomenología del espíritu. Trad. Wenceslao Roces. México D. F.: Fondo de Cultura Económica, 1973 [Edición original: 1807].

${ }^{7}$ Ver Nietzsche, Friedrich: La voluntad de poder. Trad. Aníbal Froufe. Madrid: Edaf, 2006 [Edición original: 1901].

${ }^{8}$ Ver Husserl, Edmund: Investigaciones lógicas. Trads. Manuel G. Morente y José Gaos. I y II Vol. Madrid: Alianza, 2006 [Edición original: 1900-1901].

${ }^{9}$ Indígenas y mujeres, las indias eran Otras al cuadrado, como demuestra la crudeza de este relato de Michele de Cuneo, acompañante de Colón en una de sus expediciones: "Mientras estaba en la barca, hice cautiva a una hermosísima mujer caribe, que el susodicho almirante me regaló, y después de que la hube llevado a mi camarote, y estando ella desnuda según es su costumbre, sentí deseos de holgar con ella. Quise cumplir mi deseo, pero ella no lo consintió y me dio tal trato con sus uñas que hubiera preferido no haber empezado nunca. Pero al ver esto (...), tomé una cuerda y le di azotes, después de los cuales echó grandes gritos, tales que no hubieras podido creer tus oídos. Finalmente llegamos a estar tan de acuerdo que puedo decirte que parecía haber sido criada en una escuela de putas". Citado en Todorov, Tzvetan: "Descubrir". La Conquista de América: el problema del otro. Trad. Flora Botton. México D.F.: Siglo XXI, 1998 [Edición original: 1982]. 13-58, p. 56.

${ }^{10}$ Como los cuerpos en movimiento de Galileo y Newton, los individuos (los privilegiados, olvidó matizar Hobbes) gozan de una extrema libertad primigenia. Ver Hobbes, Thomas: Leviatán. Trad. Antonio Escohotado. Madrid: Editora Nacional, 1980 [Edición original: 1651].

11 Ver nota 29 sobre John Locke.

${ }^{12}$ Frank, André G.: Re-orientar: la economía global en la era del predominio asiático. Trad. Pablo Sánchez. Valencia: Universidad de Valencia, 2008 [Edición original: 1998], p. 81. La hegemonía europea no tiene más de dos siglos, desde finales del XVIII o comienzos del XIX, y no cinco como tradicionalmente se subraya. Historiadores como Pomeranz coinciden en la misma tesis. Ver
} 
multilateral aupados por la extracción colonial, tanto material como humana ${ }^{13}$. Solo la influencia de las periferias (lo Otro que Europa) en lo Mismo (Europa), y no así ninguna cualidad excepcional, permitió a Europa acceder a la economía mundial. Aun así, lo hizo como jugadora de segunda fila ${ }^{14}$.

Nuevamente, ¿por qué entonces acabó triunfando Europa? El declive de Oriente precedió al auge de Occidente como dos fenómenos codependientes que se cruzaron en un horizonte global, en torno a 1815. Entrada la Modernidad madura o segunda Modernidad (1815-1945), un conjunto de causalidades no estructurales ${ }^{15}$, fruto de su inserción en la economía mundial, impidieron que China dedicara el campesinado necesario para la producción de mercancías que requería una revolución industrial. Las condiciones sí las reunía Inglaterra, que aprovechó para reducir los costes de producción a través de la mecanización de mano de obra. La Revolución Industrial lanza a Europa a un progreso inesperado, lo que disipa lentamente la competencia asiática.

La burguesía generada al calor de las diferencias triunfantes es la que da el espaldarazo definitivo a la Ilustración. Son dos siglos (XVIII y XIX) de hegemonía científica, tecnológica y política, donde Kant y el idealismo germano se erigen en uno de los focos del devenir europeo, que moldea a su antojo a las periferias ${ }^{16}$. Europa afianza su liderazgo militar, lo que le permite mantener un dominio sobre el mundo (latino)americano al igual que sobre el colonial asiático; en otras latitudes, las ÁfricaS son descuartizadas y repartidas como trofeo (Congreso de Berlín, 1884-1885) además de explotadas.

Cronológicamente hablando, el momento posterior es el que discurre entre los dos grandes conflictos bélicos, con la deshumanización radical del hombre, convertido en máquina de guerra. También coincide en el tiempo la emancipación de las colonias asiáticas y africanas, en un ejercicio de liberación limitada y parcial en el que se mantienen las fuertes marcas de la etapa colonial,

Pomeranz, Kenneth: The Great divergence: Europe, China, and the making of the modern world economy. Princeton: Princeton University Press, 2000.

${ }^{13}$ Las colonias resultaron muy rentables para Europa: generaban recursos adicionales en forma de metales preciosos (plata y oro), alimentos (papas, maíz, tomate, chocolate, azúcar) y textiles (seda, algodón), además de seres humanos convertidos en recursos. Aparte, servían de válvula de escape a la que recurrían las potencias europeas para destinar a sus masas empobrecidas, despreocupándose de su sustento.

14 "La evidencia sugiere que el dinero que los europeos trajeron de América (...) estimuló la producción y alentó el crecimiento demográfico en muchas partes de Asia más de lo que lo hizo en la propia Europa, (...) precisamente porque las economías asiáticas eran más flexibles y productivas". En Frank, André G.: Op. Cit., pp. 195-196.

${ }^{15}$ Crecientes tensiones económicas y políticas posiblemente generadas por la inyección de plata americana (que terminó por distorsionar la distribución de ingresos), dificultades ecológicas (producto paradójicamente de su propia expansión demográfica y productiva, que provocó una sobreexplotación y una deforestación que afecto sobre manera al valle del Yangtzé), la falta de carbón (los depósitos naturales estaban situados muy lejos de las posibles localizaciones de utilización) y el coste de la alimentación de las ciudades. Ver Pomeranz, Kenneth: Op. Cit.

${ }^{16}$ El orientalismo y el occidentalismo son ocultaciones de esta época junto con la construcción del Sur de Europa como latitud despectiva: en los Pirineos comienza África.

Araucaria. Revista Iberoamericana de Filosofia, Política, Humanidades y Relaciones Internacionales, año $21, \mathrm{n}^{\circ} 42$. Segundo semestre de 2019. Pp. 45-64. ISSN 1575-6823 e-ISSN 2340-2199 doi: 10.12795/araucaria.2019.i42.03 
señales todavía hoy de difícil superación, sobre todo teniendo en cuenta la dependencia económica y política que subyace bajo la relación Norte-Sur(es) ${ }^{17}$.

La Modernidad tardía o tercera Modernidad (1945-2001) reafirma finalmente la representación que Europa hace de los Otros, ahora con la inclusión en el tablero geopolítico del imperio estadounidense. El desplome de la Unión Soviética da el pistoletazo de salida a una nueva etapa de expansión, la globalización neoliberal (a partir de 1989) y el capitalismo transnacional sin límites ${ }^{18}$, con los mismos perdedores, las periferias y la Naturaleza.

No se vislumbra otro porvenir del mundo que el regido por la exigencia de su europeización. Para los más optimistas, (...) traduce sencillamente la adopción del modelo superior, funciona como una ley necesaria que se impone por las circunstancias. (...) Para otros, los pueblos no europeos son los dueños de una decisión alternativa: o aceptan la europeización interiorizando sus exigencias o bien, si la rechazan, se encerrarán en un callejón sin salida que conduce fatalmente a su decadencia ${ }^{19}$.

\section{Razón mitológica}

Esta dicotomía se sostiene sobre la Razón excluyente de la(s) Modernidad(es), alimentada con los mitos que todavía mantienen a Europa. "El ideal europeo de humanidad se ha manifestado como un ideal más entre otros muchos, no necesariamente peor, pero que no puede pretender, sin violencia, el derecho de ser la esencia verdadera del hombre, de todo hombre" ${ }^{20}$. Ir más allá supone el abandono del discurso eurocéntrico y de su racionalidad. Ya para la filosofía griega la razón era la facultad cognoscitiva para distinguir entre lo verdadero y lo falso, fronteras, las de verdad y falsedad, que separaban aquello que realmente era de lo que parecía ser. Esto último "no es simplemente la nada; es una potencialidad y una amenaza al ser: la destrucción. (...) Es el proyecto esencialmente humano"21. Esta concepción

\footnotetext{
${ }^{17}$ Asistimos "a una nueva paradoja: los países africanos ahora oficialmente independientes pero profundamente desarticulados son orientados política, económica y culturalmente a la satisfacción de los intereses extranjeros". En Fornet-Betancourt, Raúl, y Juan Antonio Senent (eds.): Filosofia para la convivencia: caminos de diálogos norte-sur. Alcalá de Guadaíra (Sevilla): MAD, 2004, p. 136.

18 "El mundo se convirtió en un gran mercado. También laboral: la división del trabajo adquirió un carácter internacional. (...) Un poco como si toda la Tierra se hubiera convertido en una gran cadena de montaje donde cada puesto se dedicaba a pequeñas tareas inútiles e incomprensibles por sí mismas". En Rendueles, César: Op. Cit., p. 132.

${ }^{19}$ Amin, Samir: "Para una teoría de la cultura crítica del eurocentrismo". El eurocentrismo: crítica de una ideología. Trad. Rosa Cusminsky de Cendrero. Medellín: Siglo XXI Editores, 1989. 15-143, p. 103.

${ }^{20}$ Vattimo, Gianni: “Posmodernidad: ¿una sociedad transparente?” En En torno a la posmodernidad. Por Gianni Vattimo y otros. Barcelona: Anthropos, 1990. 9-19, p. 12.

${ }^{21}$ Marcuse, Herbert: El hombre unidimensional. Trad. Antonio Elorza. Barcelona: Austral, 2016 [Edición original: 1964], p. 144.
} 
clásica contiene la esencia de lo que será la futura Razón moderna: lo que distingue al Hombre frente al esclavo, al bárbaro o a la mujer. Desde sus orígenes, la racionalidad se mueve entre la esencia del ser y la potencia del no-ser. “¿Quién es (...) el sujeto que incluye en sí la condición ontológica de lo verdadero y lo falso? (...) El que domina la pura contemplación (la teoría) y (...) la práctica guiada por la teoría, esto es, el filósofo-hombre estadista. (...) La filosofía (...) deja a la historia detrás (...) y eleva la verdad sin peligro por encima de la realidad histórica" ${ }^{22}$. Esta pureza abstracta hace de la Razón un proceso inmune al mundo de vida, convirtiendo al sujeto privilegiado "en la forma pura y universal de la subjetividad" ${ }^{23}$.

El europeo moderno se topa con la cuestión de la racionalidad a finales del siglo XV y principios del XVI. Por vez primera Europa tenía enfrente a seres extraños y, al mismo tiempo, semejantes. ¿Humanos y racionales? "Especialmente centro, el ego cogito (...) se pregunta (...): ‘ ¿Son hombres los indios?', es decir, ‘¿son europeos y por ello animales racionales?"”24. Intentándose librar de tantos prejuicios, los de la tradición y los de la autoridad (civil y religiosa), pero también prescindiendo de las exterioridades, la Razón ilustrada se creyó crítica y universal. Sustentó la ausencia de limitantes en su proceso de abstracción, constituyendo así una de sus mayores miopías, pues la historicidad y las Otras son condición sine qua non de la finita razón humana. La justificación racional de la Totalidad se hizo dogmática y la razón se vio "rebajada al rango de 'racionalidad'. (...) El pecado de los ilustrados consistió (...) en no reconocer verdaderamente los límites de la razón y en no recurrir, cuando es razonable, a la ayuda de otro" 25 .

Esta racionalidad condujo a la emancipación de la humanidad (del Ser), pero también a la barbarie (con el no-ser). Todo lo real es racional y todo lo racional es real, sobre todo a partir de Hegel26. "El saber mismo, que hasta ese momento había sido una fuerza de humanización transformadora del hombre, pasa a institucionalizarse en la ciencia con independencia del hombre"27. Es un tipo de Razón trascendente al ser humano y que por eso deja de ser una

\footnotetext{
22 Ibid., p. 148.

23 Ibid., p. 153.

${ }^{24}$ Dussel, Enrique: Filosofia de la liberación. Bogotá: Nueva América, 1996, p. 15.

25 Cortina, Adela: "Razón ilustrada e idea de Dios". Ética mínima: introducción a la filosofía práctica. Madrid: Tecnos, 2007 [Edición original: 1986b]. 207-229, p. 229.

${ }^{26}$ Friedrich Hegel cierra como identidad absoluta e inmediatez totalizada cualquier conato de alteridad. Se trata de una filosofía de la identidad y de la razón absoluta aplicados a la Totalidad, por lo que al pensamiento europeo solo le resta volver sobre sus pasos, ya sea desde la derecha o desde la izquierda. Ver Hegel, G. W. Friedrich: Op. Cit. En realidad, ya antes de Hegel buena parte de la Filosofía moderna aspiró a hacer realidad el pleno dominio cognoscitivo y técnico del mundo por parte del Hombre, para lo que recurrió a absolutizar la razón lógica, reduciendo la realidad a un conjunto de leyes y regularidades de tipo matemático. Entre los principales representantes del racionalismo moderno se encuentran Descartes, Malebranche, Spinoza y Leibniz.

27 Quintanilla, M. A.: "Razón”. Diccionario de Filosofía contemporánea. Salamanca: Sígueme, 1979. 419-420, p. 419.
} 
fuerza del mismo para constituirse en una estructura independiente que acaba sometiendo al propio hombre, en lugar de estar a su servicio.

Esta Razón prevalece en el mundo moderno, a través de la ideología científica que desde el Renacimiento forma la base de los ámbitos dominadores del pensamiento. Se trata de una ideología que "va a crear un orden propio de objetividad (el mercado y sus leyes en el ámbito social), que lleva a la aniquilación del individuo. (...) La realidad es una realidad de objetos y el hombre mismo llega a ser un objeto más dentro del conjunto" ${ }^{28}$. La racionalidad no es ya la humana sino la sistémica. 'El sueño de la razón produce monstruos', reza el célebre motto de la lámina 43 de Los Caprichos del pintor Francisco de Goya. Y es cierto, "la razón sola, dormida, sin las demás virtudes, lo hace" 29. Esta racionalidad es efecto y no causa de la Modernidad. Su exclusividad desemboca en la actualidad como Razón autoritaria, instrumental y patriarcal.

\section{Razón autoritaria, instrumental y patriarcal}

La Razón autoritaria (también llamada 'del cínico' o 'tautológica') es la de quien no necesita entrar a valorar otros posibles razonamientos ni mucho menos permite valorar los suyos por Otros; sencillamente, ostenta el poder y la razón es $s u$ razón. Al no partir de una pretensión de verdad sino de la tenencia de dicha verdad, su discurso es monológico. Ni siquiera participa del planteamiento de la razón discursiva, pues no atiende razonamientos ajenos. El silogismo autorreferente funciona desde una subjetividad radical y arbitraria de carácter etnocéntrico, sin ningún tipo de aperturas intersubjetivas. Se trata de una exclusión íntegra de toda disidencia o distinción, en un discurso abrazado numerosas ocasiones por la Filosofía: el ejemplo moderno más ilustrativo es la defensa que levanta Locke del esclavismo y del colonialismo ${ }^{30}$. Este modus operandi de la Razón excluyente continúa vigente y se corresponde con la

\footnotetext{
${ }^{28}$ Ibid., p. 420.

${ }^{29}$ Beuchot, Mauricio, Francisco Arenas Dolz, y Gianni Vattimo: Hermenéutica de la encrucijada: analogía, retórica y filosofia. Barcelona: Anthropos, 2008, p. 261.

30 John Locke argumenta de la siguiente forma: todos somos iguales y libres en un estado de naturaleza, hasta que alguien rompe la ley natural y queda automáticamente excluido de los márgenes de seguridad de dicha igual libertad; cualquier hombre podría juzgar y castigar al infractor, lo que acarrea un caos o un estado de guerra permanente. Es para superar estos peligros que nace la sociedad civil, con autoridad únicamente intra-estatal, es decir, que las relaciones entre Estados quedan fuera del ámbito de actuación de toda autoridad. El colonialismo y la esclavitud funcionan en un marco inter-estatal, entre Estados y no en el interior del Estado, por lo que son tratadas como situaciones de excepción: si un Estado juzga que otro ha violado la legalidad natural, lo califica de 'enemigo' y lo saca de la ley, pudiendo esclavizarlo o colonizarlo. Solo Dios podría decir algo al respecto. "Soy yo el único juez en mi propia conciencia, y el que, en el gran día, habrá de dar cuenta al juez Supremo de todos los hombres". En Locke, John: Segundo tratado sobre el gobierno civil: un ensayo acerca del verdadero origen, alcance y fin del gobierno civil. Trad. Carlos Mellizo. Madrid: Alianza, 1990 [Edición original: 1689], p. 28.
} 
actual justificación de la 'guerra justa', nosotros contra ellos (quienquiera que sea el ellos), cuyo único juez es el que propone la acción o, a lo sumo, la divinidad. El argumento tautológico representa "la total irracionalidad. La Totalidad totalizada emite un juicio desde su propio fundamento" ${ }^{31}$.

El sesgo instrumental de la Razón tecnológica es la segunda fetichización ${ }^{32}$ de la racionalidad. La Modernidad mata a Dios ${ }^{33}$ y le sustituye por el Hombre: los fundamentos morales y éticos ceden el testigo a la Razón instrumental. A través de esta experiencia del Ser, la Modernidad supuso un punto de inflexión en la ontología de la Totalidad: el hombre moderno niega al Absoluto, al Otro per se, el Dios del medievo; el ego se queda sin deidad, solo, ego solipsista erigido en Totalidad. No se trata ya de una totalidad física (la physis clásica) sino egótica, un sujeto que se constituye en el Ser del mundo. "El ego cogito es el comienzo del Ich denke de Kant y del Ich arbeite de Marx" ${ }^{34}$. Hegel refleja la plenitud de la totalización moderna: el Ser es el Saber y la Totalidad es el Absoluto $^{35}$, un Absoluto que no es physis sino Sujeto, el Sujeto propio de la racionalidad moderna.

La resurrección de la deidad hecha Hombre fue sin embargo ambivalente: "De las dos caras de la moneda del progreso, el moral y el técnico, resultó triunfadora la segunda, y fue la razón técnica (...) quien sustituyó a Dios en la tarea legitimadora" ${ }^{36}$. La subjetividad corporal queda materializada y el cuerpo humano es convertido en mera máquina. Los momentos son negados uno tras otro: la política (burocratización), las intrahistorias (ascetismo calvinista o puritano), la subjetividad (descorporalizada a través de la alienación -marxismo- o las pulsiones -psicoanálisis), la ética (entendida como ingeniería técnica), la comunidad (negada por el solipsismo ${ }^{37}$ ); incluso la vida humana, cualidad por excelencia ${ }^{38}$, es medida al peso, cosificada e introducida en el mercado. El triunfo de la Razón instrumental "hace realidad el sueño metafísico de la organización universal de todos los seres dentro de

${ }^{31}$ Dussel, Enrique: Materiales para una politica de la liberación. México D.F.: Plaza y Valdés, 2007, p. 287.

${ }^{32}$ La fetichización es el proceso por el cual a un objeto de culto se le atribuyen poderes sobrenaturales, de forma que éste se diviniza, se absolutiza. La raíz etimológica proviene del portugués feitiço, denominación con la que conocían los navegantes lusos los objetos de culto creados por los pueblos originarios; la artificialidad de los feitiços remite a su procedencia latina; facticius, inventado, del verbo facere, hacer.

${ }^{33}$ Ver Nietzsche, Friedrich W.: Así habló Zaratustra. Trad. Andrés Sánchez. Madrid: Alianza, 1998 [Edición original: 1883].

${ }^{34}$ Dussel, Enrique, y Daniel E. Guillot: "Para una fundamentación filosófica de la liberación latinoamericana". Liberación latinoamericana y Emmanuel Lèvinas. Buenos Aires: Bonum, 1975. 13-46, p. 18.

${ }^{35}$ Ver Hegel, G. W. Friedrich: Op. Cit.

${ }^{36}$ Cortina, Adela: "La Ilustración: un proyecto moral fracasado". Ética mínima: introducción a la filosofia práctica. Madrid: Tecnos, 2007 [Edición original: 1986a]. 146-152, pp. 149-150.

${ }^{37}$ Solum en latín significa solitario, desierto.

${ }^{38}$ Quien la pierde, muere; y esa preexistencia de la vida humana con respecto al mismo sujeto ético es el criterio último de verdad de todo valor. 
la estructura cada vez más previsible de causas y efectos" ${ }^{\prime 39}$. El precio que se paga por un universo cuantificable y previsible es el de una Razón enrocada en sí misma que excluye lo Otro no-medible como irracional, indeseable o inexistente.

En tercer lugar, la racionalidad que levanta la Modernidad no puede identificarse sin matices con el varón como su sujeto por excelencia, pues se trata de determinados varones vinculados a intereses o grupos sociales y valores concretos, pero sí puede afirmarse que su discurso es patriarcal,

elaborado desde la perspectiva privilegiada a la vez que distorsionada del varón, y que toma al varón como su destinatario en la medida en que es identificado como el género en su capacidad de elevarse a la autoconsciencia. (...) [Los] varones son los portadores del logos. (...) La ausencia de la mujer en este discurso (...) ni siquiera puede ser detectada como ausencia porque ni siquiera su lugar vacío se encuentra en alguna parte; la ausencia de la ausencia (...) es el logos femenino o la mujer como $\log _{0}{ }^{40}$.

Este rasgo patriarcal en la historia de la Filosofía viene de lejos, como queda evidenciado en la teoría hilemórfica que hereda la escolástica de Aristóteles $^{41}$, y en la que a la mujer le correspondía la materia, principio esencial de pasividad y alogicidad, frente a la forma del varón, manifestación de actividad e inteligibilidad. No es de extrañar que, entrada la Modernidad, a ella se le asocie con la naturaleza, pero no en su cualidad de dadora de la vida sino como aquel otro que también puede y debe ser medido, controlado y apropiado; frente a la inferior concepción de la mujer-naturaleza aparece la de varón-cultura, la cualidad que posibilita el despegue de lo inmediato y la posterior adquisición de la (auto)conciencia, sin la cual no se es, como pone de manifiesto el cogito ergo sum. La contradicción es extrema para una época

${ }^{39}$ Vattimo, Gianni: Adiós a la verdad. Trad. María Teresa D’Meza. Barcelona: Gedisa, 2010 [Edición original: 2009], pp. 134-135.

${ }_{40}$ Amorós, Celia: "Feminismo, Filosofía y razón patriarcal". Hacia una crítica de la razón patriarcal. Barcelona: Anthropos, 1985. 21-55, p. 27. Amorós aboga por una razón menos esencialista y más nominalista, orientada más a los individuos que a los géneros. En definitiva, un logos feminista pero no como razón para las mujeres ni de las mujeres, tampoco como expresión de los valores femeninos. "Existen corrientes del feminismo que seguramente verían con buenos ojos que la cuestión de una ética feminista se planteara como una reivindicación de los valores femeninos frente al imperialismo de los valores masculinos. (...) No compartimos esta actitud en la medida en que (...) puede ser profundamente ambigua. A una ética feminista le correspondería la elaboración de un nuevo concepto de la universalidad. Pues, ¿qué código de valores podría contraponer ahora el feminismo al de los valores masculinos dominantes? Estos mismos valores están considerados tales en su llamada 'complementariedad' con los femeninos, que quedan definidos de esta forma en un sistema de oposiciones que responde en última instancia a determinadas construcciones sociales tanto de la mujer como del hombre-varón. Este sistema constituye una totalidad y hay que oponerse a él como un todo". Ibid., p. 108.

${ }^{41}$ Ver Aristóteles: Acerca del alma. Trad. Tomás Calvo. Madrid: Gredos, 1988 [Edición original: ca. 330 a.e.c.].

Araucaria. Revista Iberoamericana de Filosofia, Política, Humanidades y Relaciones Internacionales, año $21, \mathrm{n}^{\circ} 42$. Segundo semestre de 2019. Pp. 45-64. ISSN 1575-6823 e-ISSN 2340-2199 doi: 10.12795/araucaria.2019.i42.03 
moderna que se jacta del descubrimiento de una Razón universal para todos los seres humanos ${ }^{42}$.

\section{Reformas en la sin-razón moderna}

No tardan en surgir críticas a la sin-razón de la racionalidad moderna. Desde el interior de la propia Modernidad, el cuestionamiento de la Razón excluyente surge de voces diversas. Quienes elevan la voz son primero los filósofos de la sospecha: Marx, Nietzsche y Freud. Considerando que la burguesía liberal no tiene suficiente fuerza histórica, Karl Marx ${ }^{43}$ muestra sin vacilaciones que el interlocutor de la Filosofía debería ser la racionalidad proveniente de la humanidad sufriente. Por su parte, la crítica nietzscheana ${ }^{44}$ a los ideales modernos es total, situando en su punto de mira a filósofos como Leibniz, Kant, Fichte, Schelling, Schopenhauer, Schleiermacher y Hegel; los grandes relatos legitimadores se baten en retirada: dialéctica del espíritu, hermenéutica del sentido, emancipación de la clase obrera, desarrollo económico, épica del progreso, etcétera; el aroma de vacío nihilista lo cubre todo. Y Sigmund Freud ${ }^{45}$ diagnostica al sujeto moderno una dolencia narcisista, provocada por su afán de alcanzar la productividad y el progreso; para lograr éstos, el ser humano reprime sus instintos, tornando incompatible su propia naturaleza humana con la sociedad civilizada.

Los diagnósticos y las terapias son variados, como puede constatarse en el paso de la razón teológica en el Medioevo europeo a la normativa por Weber, de la búsqueda del ser en los presocráticos a su pérdida en la metafísica occidental por Heidegger, o en la Dialéctica de la Ilustración por Horkheimer y Adorno. Mientras Max Weber ${ }^{46}$ pide a los utópicos una cura de realismo; para Martin Heidegger ${ }^{47}$ es necesario intentar ir más allá del horizonte ontológico del mundo, hasta abrirse a un nuevo ámbito donde será necesario un método

${ }_{42}$ Immanuel Kant, por ejemplo, considera que las facultades de los varones son superiores por naturaleza a las de las mujeres, a las que ve incapaces de emanciparse por sí mismas, relegándolas tanto en un plano jurídico-político como socio-cívico. Ver Kant, Immanuel: Observaciones sobre el sentimiento de lo bello y lo sublime. Trad. Dulce María Granja. México D. F.: Fondo de Cultura Económica, 2011 [Edición original: 1764].

${ }^{43}$ Ver Marx, Karl: El capital: crítica de la economía política. Trad. Vicente Romano. Madrid: Akal, 2000 [Edición original: 1867].

${ }^{44}$ Ver Nietzsche, Friedrich W.: La genealogía de la moral: un escrito polémico. Trad. Andrés Sánchez. Madrid: Alianza, 1972.

${ }^{45}$ Ver Freud, Sigmund: El malestar en la cultura y otros ensayos. Trad. Ramón Rey. Madrid: Alianza, 2009.

46 Ver Weber, Max: Ensayos sobre sociología de la religión. Trads. José Almaraz y Julio Carabaña. Madrid: Taurus, 1987 [Edición original: 1920].

47 Ver Heidegger, Martin: Tiempo y ser. Trads. Manuel Garrido, José Luis Molinuevo y Félix Duque. Madrid: Tecnos, 2009.

Araucaria. Revista Iberoamericana de Filosofía, Política, Humanidades y Relaciones Internacionales, año $21, \mathrm{n}^{\circ} 42$. Segundo semestre de 2019. Pp. 45-64. ISSN 1575-6823 e-ISSN 2340-2199 doi: 10.12795/araucaria.2019.i42.03 
más radical, un nuevo lenguaje; tras la denuncia de la no-verdad y el no-ser del pensamiento occidental, su viaje conduce hasta las supuestas fuentes de la racionalidad europea. Max Horkheimer ${ }^{48}$ y Theodor Adorno ${ }^{49}$ conservan, por su parte, una confianza escéptica en la capacidad emancipadora de una razón ilustrada autorreflexiva. Ultrapasando la negación de la negación, la dialéctica negativa no pretende una síntesis superior de los opuestos sino la puesta de manifiesto de la crudeza de tal oposición en la realidad ${ }^{50}$; propone la superación del sistema con otro horizonte utópico generado desde el mismo sistema y sin posibilidad de afirmar las exterioridades reales, caso similar a la fantasía artística de Marcuse ${ }^{51}$ y de los postulados de Benjamin ${ }^{52}$. Las posturas de Horkheimer y Adorno se dejan interpelar por la conciencia del destino de las víctimas de la historia como pocas otras filosofías. Pese a la diversidad de sus críticas, ninguno de estos intentos "hacían posible, como proyecto histórico, el objetivo mismo de la Dialéctica de la Ilustración: salvar la Ilustración" 53 .

Incluso los feminismos eurocentrados del siglo XX cayeron en la trampa de la universalización de una Razón excluyente, al no explicitar las conexiones entre el género, la clase, la raza y la sexualidad. Y es que, sus esfuerzos por hacer frente la caracterización de las mujeres como inferiores física y psicológicamente se centraba, explícita o implícitamente, en el sujeto-mujer representado por las

${ }^{48}$ Horkheimer no niega la Modernidad ni sus ideales emancipadores, tampoco la Razón ilustrada, sino que critica la lógica interna que convierte la libertad de las sociedades democráticas en una opción engañosa y efímera, la misma lógica que conduce a la muerte del sujeto. Pretende introducir la razón en el mundo, desde la experiencia de la historia como sufrimiento, como historia de la felicidad truncada, incumplida, de las víctimas y de la naturaleza. La Filosofía ha de hacerse Historia para reconciliar el derecho pendiente a la felicidad de las víctimas. Se sitúa así en la línea abierta por la dialéctica hegeliana, pero desde la perspectiva crítico-materialista de Marx y por un camino propio: la filosofía social. Ver Horkheimer, Max: Crítica de la razón instrumental. Trads. H. A. Murena y D. J. Vogelmann. Buenos Aires: Editorial Sur, 1967 [Edición original: 1973]

${ }_{49}$ Complemento de la postura de Horkheimer, Adorno identifica la enfermedad de la razón con la Razón misma. El más allá que proponen ambos autores no niega simplemente la propia razón, sino que al mismo tiempo la conserva, oxímoron posible en el sentido de la dialéctica hegeliana. No se trata de una afirmación metafísica sino histórico-crítica. Ver Adorno, Theodor W.: Dialéctica negativa. La jerga de la autenticidad. Trad. Alfredo Brotons. Madrid: Akal, 2005 [Edición original: 1970].

50 Este 'ultrapasando' (o 'más allá de) la negación de la negación debe ser leído en el sentido de que la dialéctica negativa no pretende quedarse anclada en la negación de la negación, sino más bien detenerse en ese momento negativo, hasta rescatar de esa experiencia la pretensión de verdad de lo no idéntico, de las exterioridades condenadas, cuya liberación propone dicha dialéctica negativa. Para una mayor profundización en esta dirección, ver ZAMORA, José Antonio: Th W. Adorno: pensar contra la barbarie. Madrid: Trotta, 2004.

${ }^{51}$ La teoría de las pulsiones de Herbert Marcuse alumbra la nueva concepción técnica de la razón. Ver Marcuse, Herbert: Eros y civilización. Trad. Juan García. Madrid: Sarpe, 1983 [Edición original: $1953]$.

52 Ver Benjamin, Walter: Tesis sobre la historia y otros fragmentos. Trad. Bolívar Echevarría. México D.F.: Universidad Autónoma de la Ciudad de México, 2008 [Edición original: 1942].

53 Sánchez, Juan José: "Introducción. Sentido y alcance de la Dialéctica de la Ilustración". Dialéctica de la Ilustración: fragmentos filosóficos. Trad. Juan José Sánchez. Eds. Max Horkheimer y Theodor W. Adorno. Madrid: Trotta, 1998. 9-46, p. 35. El autor se refiere específicamente a las posturas de Horkheimer y Adorno, en un comentario que puede extenderse al resto de sospechas.

Araucaria. Revista Iberoamericana de Filosofia, Política, Humanidades y Relaciones Internacionales, año $21, \mathrm{n}^{\circ} 42$ Segundo semestre de 2019. Pp. 45-64. ISSN 1575-6823 e-ISSN 2340-2199 doi: 10.12795/araucaria.2019.i42.03 
mujeres blancas y burguesas; sus críticas ocultaban a las mujeres racializadas, a las otras mujeres, a las colonizadas, a las no-blancas, a las periféricas, a las sureñas, a esos sujetos tantas veces caracterizados como salvajes, agresivos y dotados de una fortaleza tal que les permitía asumir cualquier trabajo. "El feminismo hegemónico blanco equiparó 'mujer blanca' y 'mujer'. (...) No se entendieron a sí mismas en términos interseccionales, en la intersección de raza, género, y otras potentes marcas de sujeción y dominación" 54 .

El logos univocista de la Razón se mantenía en pie, fortaleza ante a la que surge paulatinamente una post-Modernidad que no encuentra rasgos satisfactorios en la racionalidad autoritaria, instrumental y patriarcal, y pasa a proponer su perfeccionamiento, a través de críticas positivas como las de Apel ${ }^{55}$ o Habermas ${ }^{56}$. El callejón sin salida se sitúa en ambos casos en el a priori de la comunidad de comunicación, que funciona como imperativo categórico supremo: no se trata siquiera una comunidad científica de corte elitista sino apriorística; aun suponiendo su humanidad, la dificultad radica en "cómo articular esa comunidad trascendental de comunicación con las comunidades fácticas, y por ende históricas, en que los hombres nacen, viven y mueren (además de comunicarse unos con otros 0 , por lo menos, intentarlo)" ${ }^{\prime 57}$. La clave es la tensión que media entre el ser socio-histórico ${ }^{58}$ (comunidad real) y el deber ser moral (comunidad ideal). La tensión griega ser versus parecer-ser deja paso a la tensión ser versus deber ser; en ambos casos, el segundo término de la relación esconde al no-ser.

Apoyado en la estructura del lenguaje, Habermas basa la acción comunicativa en el consenso garantista de la racionalidad, perdiendo de vista que las razones colectivas pueden ser tan falibles como las individuales, que los acuerdos y las mayorías no siempre suman verdades. Y es que, el

${ }^{54}$ Lugones, María: “Colonialidad y género". Tabula rasa, Vol. 9 jul-dic 2008. 73-101, p. 95. Disponible en: www.revistatabularasa.org/numero09/colonialidad-y-genero/. Visitada el 1 jul 2018. Digital.

55 Karl-Otto Apel entiende que los nudos teórico-prácticos se deben a la absolutización de formas parciales de racionalidad, denuncia a partir de la cual reconstruye las dimensiones olvidadas de la razón. Ver Apel, Karl-Otto: La transformación de la filosofia. Trads. Adela Cortina, Joaquín Chamorro y Jesús Conill. Madrid: Taurus, 1985 [Edición original: 1972-1973].

${ }^{56} \mathrm{La}$ forma que presenta Jürgen Habermas para rescatar la razón práctica es la acción comunicativa. A través del componente comunicativo, revisa la teoría crítica evitando tanto el esteticismo de Adorno como el recurso final a la trascendencia de Horkheimer. Ver Habermas, Jürgen: Teoría de la acción comunicativa. Trad. Manuel Jiménez. Madrid: Taurus, 1999 [Edición original: 1981].

${ }^{57}$ Muguerza, Javier: “¿Produce monstruos el sueño de la razón?” Desde la perplejidad: ensayos sobre la ética, la razón y el diálogo. Madrid: Fondo de Cultura Económica, 2006. 570-574, p. 130.

58 Que la razón sea histórica, como no podía ser de otra manera tratándose de un ser humano histórico, no implica que sea historicista, es decir, no inmoviliza acríticamente ante lo que hay o lo que toca. Así lo advierte, entre otros, Marcuse: "Cuando el contenido histórico entra en el concepto dialéctico y determina metodológicamente su desarrollo y su función, el pensamiento dialéctico alcanza la concreción que liga la estructura del pensamiento con la realidad. La verdad lógica se convierte en verdad histórica. (...) La razón se convierte en razón histórica". En MARCUSE, Herbert: Op. Cit., p. 158. 
diálogo también corre el peligro de "acabar siendo (...) escrito con mayúscula cuando se depositan desmesuradas esperanzas en la "razón dialógica" 59 . Tras desenmascarar que la razón propuesta por la primera Escuela de Frankfurt (vía Adorno y Horkheimer) rescataba la naturaleza histórica de la razón, pero no lograba liberarse del paradigma de la dominación sujeto-objeto desde el cual es imposible superar la Razón instrumental, Habermas recupera la razón comunicativa, en un intento de reprobar los mono-logos del Gran Relato sin renunciar por ello a un concepto positivo e integral de razón. Olvida con ello que la argumentación corre el peligro de ser monopolizada por los Mismos, por quienes tienen el poder de la palabra.

Los 'otros' de la comunidad de comunicación apenas traspasan el círculo de los capaces de intervenir en el discurso. El problema anterior al diálogo, el cómo hacer llegar la palabra a los que carecen de ella (o a los que se les ha arrebatado), a los incapaces de habla, no parece perturbar excesivamente al nuevo paradigma. En último extremo, la intersubjetividad es aquí solo condición de posibilidad del consenso, pero no de la razón misma: puede haber consenso entre los hablantes, pero no razón, mientras haya excluidos del diálogo ${ }^{60}$.

\section{Conatos transformadores a la Razón moderna}

Un paso más allá se sitúan las interpretaciones de Lèvinas y de Vattimo, dos de los filósofos postmodernos con más conciencia de las otredades. Sus respectivas transformaciones a la Razón moderna se condensan en la interpelación al triple rostro del Otro levinasiano (viuda-huérfano-extranjero; en definitiva, el Infinito desde una lectura no teológica sino trans-ontológica) y en el debilitamiento de todas las estructuras, incluida la Otredad y con especial presencia de la función que desempeña el lenguaje, de Vattimo. Es desde esa hermenéutica de momentos particulares que puede hablarse del más allá que apunan ambos autores como asidero para dibujar los primeros esbozos a una Filosofía transformada.

Emmanuel Lèvinas eleva la voz frente a la(s) Modernidad(es) y su Razón excluyente, a la que echa en cara la extrema egología del cogito cartesiano; partiendo de una conciencia crítica, descentra al Sujeto desde estructuras impersonales o colectivas, para focalizarse finalmente en la primacía ética del Otro (Infinito) frente a la Totalidad, la racionalidad de la ontología fundamental. El Otro es la exigencia ética que antepone al interés económico y bélico de la racionalidad moderna. La responsabilidad por el Otro se produce en el cara-acara o encuentro con el rostro, que es alteridad irreductible y deseable, ese Otro

\footnotetext{
${ }^{59}$ Muguerza, Javier: Op. Cit., p. 574.
}

${ }^{60}$ Sánchez, Juan José: Op. Cit., p. 37. 
en tanto que Otro ${ }^{61}$ y no como mediación constitutiva de lo-Mismo. El Otro no como negación de la Totalidad ni como creación de una Totalidad inversa que la equilibre o contrarreste, sino como distinción entre lo posible y lo permitido; el ser accede al sí-mismo por la afirmación responsable del Otro, hacia quien no puede eludir su responsabilidad.

Un cuestionamiento del Mismo (...) se efectúa por el Otro. Este cuestionamiento de mi espontaneidad por la presencia del Otro se llama ética. (...) La filosofía occidental ha sido muy a menudo una ontología: una reducción del Otro al Mismo. (...) Esta primacía del Mismo fue la lección de Sócrates. No recibir nada del Otro sino lo que está en mí, como si desde toda la eternidad yo tuviera lo que me viene de fuera. (...) Su sentido último reside en esta permanencia en el Mismo, que es Razón. (...) Que la razón sea a fin de cuentas la manifestación de una libertad que neutraliza lo otro y que lo engloba no puede sorprender, desde que se dijo que la razón soberana solo se conoce a sí misma. (...) La neutralización del Otro (...) es precisamente su reducción al Mismo ${ }^{62}$.

Gianni Vattimo, por su parte, deja de hablar de la historia como un proceso lineal, como el centro desde el que se ordenan los acontecimientos. Con el fin del relato unitario llega la imposibilidad del progreso unívoco y también de cualquier ideal de hombre, incluido el moderno Hombre europeo sustituto de Dios. Sin fundamento último y estable, Vattimo reivindica "el carácter plural de los 'relatos' (...) como elemento liberador"63. Denunciada la propia desmitificación moderna como mito, éste recupera su experiencia en forma de verdad intermitente y fragmentada. "Ya no hay evidencia apodíctica, aquélla en la que los pensadores (...) de la metafísica buscaban un fundamentum absolutum et inconcussum. El sujeto postmoderno, si busca en su interior alguna certeza primera, no encuentra la seguridad del cogito cartesiano, sino las intermitencias del corazón proustiano, los relatos de los media, las mitologías evidenciadas por el psicoanálisis" ${ }^{4}$.

El planteamiento del italiano llega de esta forma a una encrucijada. Una vez desenmascarada la Razón excluyente como fetiche que ordena ideológicamente la realidad, su reconstrucción bordea titubeante el relativismo radical de esencia

${ }^{61}$ El Otro en tanto que Otro levinasiano también puede ser leído desde una hermenéutica teológica como la alteridad de lo Perfecto, el Bien supremo, es decir, Dios. Se trata de una interpretación cuestionable y cuestionada: "El resultado levinasiano no es teológico: es un intento filosófico de analizar una experiencia ética distinta a la griega y la moderna europea. La acusación de teología del pensar levinasiano es una manera cómoda de evitar el trabajo de entenderlo". En Dussel, Enrique: Posmodernidad y transmodernidad: diálogos con la filosofia de Gianni Vattimo. Puebla: Universidad Iberoamericana, 1999, p. 30.

62 Lèvinas, Emmanuel: Totalidad e infinito: ensayo sobre la exterioridad. Salamanca: Sígueme, 2002 [Edición original: 1961], p. 67.

63 Vattimo, Gianni: La sociedad transparente. Trad. Teresa Oñate. Barcelona: Paidós, 1990 [Edición original: 1989], p. 110.

64 Ibid., p. 132.

Araucaria. Revista Iberoamericana de Filosofia, Política, Humanidades y Relaciones Internacionales, año $21, \mathrm{n}^{\circ} 42$. Segundo semestre de 2019. Pp. 45-64. ISSN 1575-6823 e-ISSN 2340-2199 doi: 10.12795/araucaria.2019.i42.03 
nihilista: "La razón univocista corre el riesgo de desembocar en una razón equivocista" ${ }^{95}$. Vattimo salva el obstáculo mediante un debilitamiento no relativista de la Verdad: 'Es una despedida de la verdad como reflejo 'objetivo' de un dato que, para ser descrito de forma adecuada, debe fijarse como estable, es decir, como 'dado'. (...) La verdad (...) no es la correspondencia objetiva, sino el horizonte paradigmático dentro del cual toda correspondencia es verificable" ${ }^{66}$. Pero una vez superada la ontología sin caer en el relativismo, no se atreve a plantear un más allá de la ontología (trans-ontología) desde las periferias. "Toca el problema (...) de la 'ontología de la libertad' (...), pero no se plantea siquiera el problema de un 'másallá' de la ontología hermenéutica" ${ }^{97}$ y se queda en una hermenéutica del ethos postmoderno, deudora todavía en exceso del solipsismo ontológico heideggeriano (el Dasein, ese yo-nosotros autosuficiente) y de la hermenéutica gadameriana (criticidad focalizada en un Lebenswelt concreto). Entre las violencias que Vattimo descubre en la racionalidad moderna no figura la que aniquila a las Otras razones no-europeas, tal vez por su misma posición eurocéntrica ${ }^{68}$. Tampoco incluye al Otro económico, como sucede con la mayoría de los filósofos norcéntricos y sin el cual es imposible abogar por transformaciones de raíz, radicales.

\section{Las transformaciones pendientes}

Aunque apenas vislumbrada, la incidencia del Otro plural en la racionalidad es incuestionable a partir de Lèvinas y Vattimo, lo que invita a pensar un el logos humano eminentemente ético, en un logos que se origina y nutre en cada encuentro con los Otros. No se trata de negar la Razón sino de ir más allá de ésta, allí donde no necesariamente se encuentran la sin-razón ni la irracionalidad, que además "frecuentemente pasa por ser lo supremamente racional, como la Idea de Hegel, el Übermensch de Nietzsche, la Raza de Hitler, el Manifest destiny o el American way of life de Estados Unidos... numerosos mitos irracionales que fundan empresas sumamente (...) 'razonables" ${ }^{69}$. No se trata de hacer concesiones al irracionalismo, sino de mantener una ontología ética que cuestione continuamente los olvidos, fabricados o inconscientes, del logos humano. No se trata de renunciar a la razón sino a escribirla en mayúscula

${ }^{65}$ Beuchot, Mauricio, Francisco Arenas Dolz, y Gianni Vattimo: Op. Cit., p. 377.

${ }^{66}$ Vattimo, Gianni (2009/2010): Op. Cit., pp. 16-17. La parábola que resume el pensiero debole es el paso de la Verdad a la caridad, evitando así la arbitrariedad y su relativismo absoluto.

${ }^{67}$ Dussel, Enrique: La ética de la liberación: ante el desafio de Apel, Taylor y Vattimo; con respuesta crítica inédita de K.-O. Apel. México D.F.: Universidad Autónoma del Estado de México, 1998, p. 166.

${ }_{68}$ "Lo abstracto, pre-pragmático, pre-ético y pre-económico del pensamiento de Vattimo, como de la filosofía europeo-norteamericana en general, pareciera ser un efecto del aislamiento que Europa tiene (y acrecienta) del Sur, de la pobreza, de la violencia que se ejerce sobre África, Asia, América Latina, en la salvaguarda de sus propios intereses". En Ibid., p. 173.

${ }^{69}$ Dussel, Enrique (1996): Op. Cit., pp. 85-86. 
y en singular, a circunscribirla al monopolio occidental. No se trata de negar el potencial instrumental de la racionalidad, sino su absolutización utilitarista. No se trata de abandonar la razón crítica, sino el racionalismo ideológico. Es, en definitiva, la transformación de debilitar y abrir la moderna Razón excluyente con y desde las Otras: "En oposición a la tesis de que la razón es un atributo exclusivo de una comunidad humana o de un pueblo, asumimos que ésta es común a todo sujeto social humano (...). La razón es un atributo de un ser (...) que piensa, analiza, critica, cuestiona" ${ }^{\circ}$.

La razón no puede estar situada contra las necesidades de las periferias, sino que su logos debe ser ético. Es la transformación de la racionalidad ontológica en éticas de justicia histórica. Donde la filosofía reflejo de la Razón excluyente busca la identidad de lo Mismo que ya es, la transformación de la Filosofía en un juego de espejos virados hacia nos-Otras, las víctimas, revela la exterioridad del Ser, el no-ser condenado que no está contra la verdad pero la debilita como construcción ontológica fabricada, como "el saber (logos) del ser (...) que la filosofía europea siempre pensó, de Sócrates a Heidegger, como condición preliminar para el acceso a los entes" "71 , como una reducción del Otro plural a lo Mismo.

El fracaso definitivo de la razón sería que la esperanza de las víctimas quedara definitivamente frustrada. De ahí, "no se pretende el descrédito de la razón sino su logro, cargar a la razón de experiencia. De su consideración se desprende (...) una razón anamnética, extraña a la Ilustración, pero en sí misma emancipatoria y, por ende, ilustrada"72. Se impone debilitar la razón sin perder de vista que no todo puede estar permitido, sin olvidar el desafío que lanzan las víctimas pasadas, presentes y futuras. Sin olvidar los cimientos filosófico-históricos de esa moderna Razón excluyente. Pero sin olvidar tampoco que la Modernidad no se resume en lo racional-científico-técnico de la Razón excluyente, ni que el saber racional también está presente en otras culturas y épocas históricas ${ }^{73}$. Las periferias exigen una definición de Modernidad alternativa, en la que la cuestión central sea la liberación de la humanidad en su conjunto.

70 Cerutti, Horacio, y Mario Magallón: Historia de las ideas latinoamericanas: ¿disciplina fenecida? México D.F.: Casa Juan Pablos, 2003, pp. 99-100.

${ }^{71}$ Vattimo, Gianni: La secularización de la filosofia: hermenéutica y posmodernidad. Trads. Carlos Cattroppi y Margarita N. Mizgraji. Barcelona: Gedisa, 1992, p. 76.

72 Mate; Reyes: "Ilustración y espíritu judío o la razón de los vencidos". En La razón de los vencidos. Barcelona: Anthropos, 1991. 7-26, p. 13.

73 'Con todas sus respectivas particularidades y diferencias, todas las llamadas 'altas culturas' (China, India, Egipto, Grecia, Maya-Azteca, Tawantinsuyo) anteriores al actual sistema-mundo muestran inequívocamente las señales de esa modernidad, incluido lo racional-científico, la secularización del pensamiento, etc. En verdad, a estas alturas de la investigación histórica, sería casi ridículo atribuir a las altas culturas no-europeas una mentalidad mítico-mágica como rasgo definitorio, por ejemplo, en oposición a la racionalidad y a la ciencia de Europa. (...) Lo más que realmente puede decirse es que, en el actual período, se ha ido más lejos en el desarrollo científico-tecnológico y se han hecho mayores descubrimientos y realizaciones, con el papel hegemónico de Europa y, en general, de Occidente”. En Quijano, Aníbal: "Colonialidad del poder, eurocentrismo y América Latina". La colonialidad del saber. Eurocentrismo y ciencias sociales, perspectivas latinoamericanas. Ed. Edgardo Lander. Buenos Aires: CLACSO, 2000. 201-246, pp. 212-213.

Araucaria. Revista Iberoamericana de Filosofia, Política, Humanidades y Relaciones Internacionales, año $21, \mathrm{n}^{\circ} 42$ Segundo semestre de 2019. Pp. 45-64. ISSN 1575-6823 e-ISSN 2340-2199 doi: 10.12795/araucaria.2019.i42.03 


\section{Referencias bibliográficas:}

\section{Principal (citada expresamente en este artículo)}

Amin, Samir: "Para una teoría de la cultura crítica del eurocentrismo". El eurocentrismo: crítica de una ideología. Trad. Rosa Cusminsky de Cendrero. Medellín: Siglo XXI Editores, 1989. 15-143.

Amorós, Celia: "Feminismo, Filosofía y razón patriarcal". Hacia una crítica de la razón patriarcal. Barcelona: Anthropos, 1985. 21-55.

Beuchot, Mauricio, Francisco Arenas Dolz, y Gianni Vattimo: Hermenéutica de la encrucijada: analogía, retórica y filosofía. Barcelona: Anthropos, 2008.

Cerutti, Horacio, y Mario Magallón: Historia de las ideas latinoamericanas: ¿disciplina fenecida? México D.F.: Casa Juan Pablos, 2003.

Cortina, Adela: "La Ilustración: un proyecto moral fracasado". Ética mínima: introducción a la filosofía práctica. Madrid: Tecnos, 2007 [Edición original: 1986a]. 146-152.

Cortina, Adela: "Razón ilustrada e idea de Dios". Ética mínima: introducción a la filosofía práctica. Madrid: Tecnos, 2007 [Edición original: 1986b]. 207-229.

Dussel, Enrique: Caminos de liberación latinoamericana II: teología de la liberación y ética. Buenos Aires: Latinoamérica Libros, 1974.

Dussel, Enrique: Filosofía de la liberación. Bogotá: Nueva América, 1996.

Dussel, Enrique: Posmodernidad y transmodernidad: diálogos con la filosofía de Gianni Vattimo. Puebla: Universidad Iberoamericana, 1999.

Dussel, Enrique: La ética de la liberación: ante el desafio de Apel, Taylor y Vattimo; con respuesta crítica inédita de K.-O. Apel. México D.F.: Universidad Autónoma del Estado de México, 1998.

Dussel, Enrique: Materiales para una política de la liberación. México D.F.: Plaza y Valdés, 2007.

Dussel, Enrique y Daniel E. Guillot: "Para una fundamentación filosófica de la liberación latinoamericana". Liberación latinoamericana y Emmanuel Lèvinas. Buenos Aires: Bonum, 1975. 13-46.

Fornet-Betancourt, Raúl, y Juan Antonio Senent (eds.): Filosofía para la convivencia: caminos de diálogos norte-sur. Alcalá de Guadaíra (Sevilla): MAD, 2004.

Frank, André G.: Re-orientar: la economía global en la era del predominio asiático. Trad. Pablo Sánchez. Valencia: Universidad de Valencia, 2008 [Edición original: 1998]. 
Horkheimer, Max y Theodor Adorno: Dialéctica de la Ilustración. Fragmentos filosóficos. Madrid: Trotta, 1998.

Lèvinas, Emmanuel: Totalidad e infinito: ensayo sobre la exterioridad. Trad. Miguel García-Baró. Salamanca: Sígueme, 2002 [Edición original: 1961]. Locke, John: Segundo tratado sobre el gobierno civil: un ensayo acerca del verdadero origen, alcance y fin del gobierno civil. Trad. Carlos Mellizo. Madrid: Alianza, 1990 [Edición original: 1689].

Lugones, María: “Colonialidad y género”. Tabula rasa, Vol. 9 jul-dic 2008. 73101. Disponible en: www.revistatabularasa.org/numero09/colonialidad-ygenero/. Visitada el 1 jul 2018. Digital.

Marcuse, Herbert: El hombre unidimensional. Trad. Antonio Elorza. Barcelona: Austral, 2016 [Edición original: 1964].

Mate; Reyes: "Ilustración y espíritu judío o la razón de los vencidos". En La razón de los vencidos. Barcelona: Anthropos, 1991. 7-26.

Muguerza, Javier: “¿Produce monstruos el sueño de la razón?” Desde la perplejidad: ensayos sobre la ética, la razón y el diálogo. Madrid: Fondo de Cultura Económica, 2006. 570-574.

Quijano, Aníbal: “Colonialidad del poder, eurocentrismo y América Latina”. La colonialidad del saber. Eurocentrismo y ciencias sociales, perspectivas latinoamericanas. Ed. Edgardo Lander. Buenos Aires: CLACSO, 2000. 201-246.

Quintanilla, M. A.: "Razón”. Diccionario de Filosofía contemporánea. Salamanca: Sígueme, 1979. 419-420.

Rendueles, César: Capitalismo canalla: una historia personal del capitalismo a través de la literatura. Barcelona: Seix Barral, 2015.

Todorov, Tzvetan: "Descubrir". La Conquista de América: el problema del otro. Trad. Flora Botton. México D.F.: Siglo XXI, 1998 [Edición original: 1982]. 13-58.

Vattimo, Gianni: La sociedad transparente. Trad. Teresa Oñate. Barcelona: Paidós, 1990 [Edición original: 1989].

Vattimo, Gianni: “Posmodernidad: ¿una sociedad transparente?” En torno a la posmodernidad. Por Gianni Vattimo y otros. Barcelona: Anthropos, 1990. 9-19.

Vattimo, Gianni: La secularización de la filosofia: hermenéutica y posmodernidad. Trads. Carlos Cattroppi y Margarita N. Mizgraji. Barcelona: Gedisa, 1992.

Vattimo, Gianni: Adiós a la verdad. Trad. María Teresa D’Meza. Barcelona: Gedisa, 2010 [Edición original: 2009]. 


\section{Secundaria (recomendada en este artículo)}

Adorno, Theodor W.: Dialéctica negativa. La jerga de la autenticidad. Trad. Alfredo Brotons. Madrid: Akal, 2005 [Edición original: 1970].

Aristóteles: Acerca del alma. Trad. Tomás Calvo. Madrid: Gredos, 1988 [Edición original: ca. 330 a.e.c.].

Apel, Karl-Otto: La transformación de la filosofía. Trads. Adela Cortina, Joaquín Chamorro y Jesús Conill. Madrid: Taurus, 1985 [Edición original: 1972-1973].

Benjamin, Walter: Tesis sobre la historia y otros fragmentos. Trad. Bolívar Echevarría. México D.F.: Universidad Autónoma de la Ciudad de México, 2008 [Edición original: 1942].

Freud, Sigmund: El malestar en la cultura y otros ensayos. Trad. Ramón Rey. Madrid: Alianza, 2009.

Habermas, Jürgen: Teoría de la acción comunicativa. Trad. Manuel Jiménez. Madrid: Taurus, 1999 [Edición original: 1981].

Hegel, G. W. Friedrich: Fenomenología del espíritu. Trad. Wenceslao Roces. México D. F.: Fondo de Cultura Económica, 1973 [Edición original: 1807].

Heidegger, Martin: Tiempo y ser. Trads. Manuel Garrido, José Luis Molinuevo, y Félix Duque. Madrid: Tecnos, 2009.

Hobbes, Thomas: Leviatán. Trad. Antonio Escohotado. Madrid: Editora Nacional, 1980 [Edición original: 1651].

Horkheimer, Max: Crítica de la razón instrumental. Trads. H. A. Murena y D.

J. Vogelmann. Buenos Aires: Editorial Sur, 1967 [Edición original: 1973]. Husserl, Edmund: Investigaciones lógicas. Trads. Manuel G. Morente y José

Gaos. I y II Vol. Madrid: Alianza, 2006 [Edición original: 1900-1901].

Kant, Immanuel: Observaciones sobre el sentimiento de lo bello y lo sublime.

Trad. Dulce María Granja. México D. F.: Fondo de Cultura Económica,

2011 [Edición original: 1764].

Marcuse, Herbert: Eros y civilización. Trad. Juan García. Madrid: Sarpe, 1983 [Edición original: 1953].

Marx, Karl: El capital: crítica de la economía política. Trad. Vicente Romano. Madrid: Akal, 2000 [Edición original: 1867].

Nietzsche, Friedrich W.: La genealogía de la moral: un escrito polémico. Trad. Andrés Sánchez. Madrid: Alianza, 1972.

Nietzsche, Friedrich W.: Así habló Zaratustra. Trad. Andrés Sánchez. Madrid: Alianza, 1998 [Edición original: 1883].

Nietzsche, Friedrich W.: La voluntad de poder. Trad. Aníbal Froufe. Madrid: Edaf, 2006 [Edición original: 1901]. 
Pomeranz, Kenneth: The Great divergence: Europe, China, and the making of the modern world economy. Princeton: Princeton University Press, 2000.

Sandoval, Canek: "Teoría de la guerra justa de Ginés de Sepúlveda: prototipo imperialista y cristiano". Ed. Hernanz, José Antonio. Xalapa: Universidad Veracruzana, 2013. [TFG No publicado].

Weber, Max: Ensayos sobre sociología de la religión. Trads. José Almaraz y Julio Carabaña. Madrid: Taurus, 1987 [Edición original: 1920].

Zamora, José Antonio: Th W. Adorno: pensar contra la barbarie. Madrid: Trotta, 2004. 